\title{
Evidence for changes in segmental motoneurone pools by chronic cerebellar stimulation and its clinical significance
}

\author{
MORRISA. FISHER AND RICHARD D. PEN N \\ From the Departments of Neurological Sciences (Laboratory of Clinical Neurophysiology) and \\ Neurosurgery, Rush-Presbyterian-St Luke's Medical Center, Chicago, Illinois, USA
}

SUMMARY Electrophysiological studies in eight patients with severe motor system abnormalities are described both before and after the start of chronic electrical stimulation of the anterior cerebellum. With stimulation, at least one of following changes was found in seven of these eight patients: reversal of abdominal $F$ amplitude ratios (flexor/extensor muscles), decreased prominence of $F$ responses, and loss of $H$ reflexes in at least one muscle other than the soleus. These changes indicate that cerebellar stimulation can affect the excitability of segmental motoneurone pools. Although clinical changes, particularly decrease in tone, were observed in all the patients with stimulation, the complexity of trying to relate the physiological findings to functional improvement is emphasised.

Chronic electrical stimulation of the anterior cerebellum has been reported to reduce rigidity in patients with motor system disorders (Cooper et al., 1973). The theoretical justification for this procedure stems partially from the observation that decerebrate rigidity in animals decreases with repeated surface electrical stimulation of the paleocerebellum (Sherrington, 1898; Dow and Moruzzi, 1958).

It is difficult to evaluate a procedure such as chronic cerebellar stimulation. The patients chosen are invariably diverse. Definition of specific clinical criteria for following these severely affected individuals is not easy, especially when trying to monitor the effect of treatment. Clinically testable physiological variables could be helpful both for establishing if the procedure was indeed producing a physiological change and for defining the nature of such an effect. Previous work (Upton and Cooper, 1976) has suggested that such an approach can be useful. In this report we discuss evidence of changes in segmental motoneurone pools with cerebellar stimulation and its clinical significance.

Address for reprint requests: Dr M. A. Fisher, Department of Neurological Sciences, EMG Laboratory, Rush-Presbyterian-St Luke's Medical Center, 1753 West Congress Parkway, Chicago, Illinois 60612, USA.

Accepted 1 February 1978

\section{Methods}

Eight patients with severe motor system deficits selected for treatment with chronic electrical stimulation of the cerebellum were chosen from a large group of patients (primarily with a diagnosis of "cerebral palsy") because of their severe motor involvement, relatively normal intellectual function, and lack of improvement with standard treatments.

Some of the clinical characteristics of these patients are shown in Table 1: all were examined personally by the authors. Tone was defined as resistance to passive movement. The abnormal movements listed were those that could be readily discerned clinically. All but one of these patients would meet the criteria for a diagnosis of "cerebral palsy"- that is, motor abnormalities which could be related to problems either at birth or during the neonatal period. One of the patients (AB) suffered midbrain trauma in an automobile accident two years before this study. The patients had an extensive evaluation both before and after surgery. Electrodes were placed anteriorly over the cerebellar surface through small suboccipital craniotomies. The electrode wires were connected to subcutaneous receivers. Stimulus parameters could be controlled externally using an adjustable transmitter. More detailed discussions of some 
Table 1 Clinical characteristics of patients studied

\begin{tabular}{|c|c|c|c|c|c|c|}
\hline Patient & $\begin{array}{l}\text { Age } \\
(y r)\end{array}$ & $\begin{array}{l}\text { Antecedent } \\
\text { history }\end{array}$ & Tone & Babinski & $\begin{array}{l}\text { Phasic } \\
\text { stretch } \\
\text { reflexes }\end{array}$ & $\begin{array}{l}\text { Movement } \\
\text { abnormality }\end{array}$ \\
\hline $1(\mathrm{MJ})$ & 30 & $\begin{array}{l}\text { neonatal } \\
\text { jaundice }\end{array}$ & \pm inc & no & $\pm \mathbf{N}$ & athetosis \\
\hline $2(\mathrm{AB})$ & 16 & $\begin{array}{l}\text { automobile } \\
\text { accident }\end{array}$ & inc* & yes* & inc* & dysmetria \\
\hline 3 (MM) & 16 & premature & inc & \pm & inc & - \\
\hline $4(\mathrm{CC})$ & 11 & premature & inc & \pm & $\mathbf{N}$ & - \\
\hline 5 (CE) & 6 & premature & inc & \pm & inc & - \\
\hline $6(\mathrm{FB})$ & 22 & $\begin{array}{l}\text { neonatal } \\
\text { hypoxia }\end{array}$ & $\doteq$ inc & yes & \pm inc & athetosis \\
\hline 7 (PP) & 30 & $\begin{array}{l}\text { neonatal } \\
\text { hypoxia }\end{array}$ & \pm inc & $\therefore$ & $\mathrm{N}$ to $\mathrm{dec}$ & dysmetria \\
\hline 8 (BS) & 24 & $\begin{array}{l}\text { neonatal } \\
\text { hypoxia }\end{array}$ & $=$ inc & no & \pm inc & $\begin{array}{l}\text { athetosis } \\
\text { dysmetria }\end{array}$ \\
\hline
\end{tabular}

$\mathrm{N}=$ normal; inc $=$ increased $;$ dec $=$ decreased $\pm=$ equivocal finding, $*=$ left side only.

aspects of the evaluation given to these patients as well as of the procedure for electrode implantation and subsequent stimulation are available elsewhere (Penn and Etzel, 1977; Penn et al., 1978).

The $\mathrm{F}$ responses or $\mathrm{H}$ reflexes or both were obtained in a standardised fashion from flexor and extensor muscles in the lower extremities. Surface electrodes were used. In all eight patients, recordings were made from the bellies of the medial aspect of the soleus (MS) and tibialis anterior (TA) muscles with the electrodes separated by $50 \mathrm{~mm}$. The active electrodes were proximal and placed halfway between the mid-popliteal crease and the medial malleolus for the MS, and halfway between the tibial tubercle and the ankle joint for the TA. In six of the patients, similar studies were performed on the abductor hallucis (AH), and in five of these on the extensor digitorum (EDB) as well. Recordings were made from these muscles in the standard belly-tendon manner. Stimuli were given to the peroneal nerve at the ankle and fibular head as well as to the posterior tibial nerve in the region of the medial malleolus and the popliteal fossa when recording from the EDB, TA, $\mathrm{AH}$, and MS muscles respectively. Stimulus duration could be varied from 0.05 to $1 \mathrm{~ms}$ and stimulus amplitude to a maximum of 300 volts (TECA NS6).

The stimuli were administered using a $30 \mathrm{~mm}$ fixed mount bipolar electrode (TECA 6030-1). For $F$ responses, the stimulating cathode was distal, the frequency $0.5 \mathrm{~Hz}$, and the stimulus duration as short as possible combined with a stimulus voltage adequate to produce a direct motor (M) response $25 \%$ supramaximal. When studying $\mathrm{H}$ reflexes, the stimulating cathode was proximal, the stimulus frequency $0.2 \mathrm{~Hz}$ (allowing adequate recovery time between stimuli), and the stimulus duration $1 \mathrm{~ms}$ (in order to activate selectively the larger afferent fibres) (Hugon, 1973). The stimulus intensity was submaximal for the $\mathbf{M}$ response with the voltage adjusted so as to produce a maximal $\mathrm{H}$ reflex. Criteria for distinguishing $\mathrm{H}$ and $\mathrm{F}$ waves have been published (Shahani and Young, 1976). During the studies, the patients were supine and as relaxed as possible. Data were analysed only if the baseline activity was such that it would not interfere with seeing the low amplitude $F$ responses, that is, only if there was little if any extraneous muscle activity.

The $\mathrm{F}$ amplitudes were measured peak-to-peak, and average $F$ amplitudes were calculated if at least five measurable responses were obtained from a particular muscle. Ratios for average $F$ amplitudes divided by maximal evoked motor response (average $\mathrm{F} /$ maximal $\mathrm{M}$ ) ranged from 0.9 to $10 \%$. If the data were available, average $\mathrm{F}$ amplitude flexor/extensor $(\mathrm{Fl} / \mathrm{Ex})$ ratios were determined for muscles acting at a common joint, that is, TA/MS or EDB/AH. Normally, the prominence of $\mathrm{F}$ responses is less in physiological flexor than in extensor muscles (Fisher, 1978). This is true for both $F$ persistence (that is, the fraction of discernible $F$ responses found after a series of supramaximal stimuli), and for average $F$ amplitude. An average $\mathrm{F}$ amplitude $\mathrm{Fl} / \mathrm{Ex}$ ratio of 1.5 or greater was at least $50 \%$ higher than that found in normal subjects and was considered abnormal.

The electrophysiological techniques used in this study are, of course, routine procedures and well tolerated. All the patients were examined as part of the routine protocol used in patients treated with chronic cerebellar stimulation.

\section{Results}

Table 2 shows the main physiological changes associated with cerebellar stimulation. All patients were studied within seven to 16 days after surgery, and no sooner than two and no later than seven days after cerebellar stimulation was begun.

In two patients (cases 1 and 2), significant reversals were found in $\mathrm{F}$ response amplitude $\mathrm{Fl} /$ Ex ratios recording from the TA and MS muscles. Recordings from the EDB and $\mathrm{AH}$ muscles were not obtained in these patients. In both patients, the TA/MS ratios on the left were 1.9 before stimulation. After the start of right cerebellar stimulation, the comparable ratio in case 1 was 0.17 (Figure) while in case 2 too few $F$ responses could be obtained from the TA for measurement. $\mathrm{F}$ persistence was 0.10 compared to 1.00 prestimulation.

In case 3, abnormal $\mathrm{Fl} / \mathrm{Ex}$ ratios were found 
Table 2 Summary of electrophysiological changes with cerebellar stimulation

\begin{tabular}{|c|c|c|c|c|}
\hline \multirow[t]{2}{*}{ Patient } & \multicolumn{2}{|l|}{ H reflexes present* } & \multicolumn{2}{|l|}{$F$ amplitude $F 1 / E x$ ratios** } \\
\hline & Before & After & Before & After \\
\hline $\begin{array}{l}1(\mathrm{MJ}) \\
2\left(\mathrm{AB}^{+}\right) \\
3(\mathrm{MM})\end{array}$ & $\begin{array}{l}\overline{-} \\
\text { L-TA,AH; R-AH }\end{array}$ & $\begin{array}{l}\overline{-} \\
\text { L-TA,AH; R-AH }\end{array}$ & $\begin{array}{l}\text { L-TA/MS } 1.90 \\
\text { L-TA/MS } 1.90 \\
\text { L-TA/MS } 2.24 ; \text { R-TA/MS } 2.05 \\
\text { R-EDB/AH } 3.00\end{array}$ & 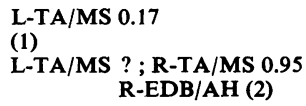 \\
\hline $\begin{array}{l}4 \text { (CC) } \\
5 \text { (CE) } \\
6 \text { (FB) } \\
7 \text { (PP) } \\
8 \text { (BS+) }\end{array}$ & $\begin{array}{l}\text { L-TA,AH; R-TA,AH } \\
\text { L-TA,AH; R-AH } \\
\text { L-AH } \\
- \\
-\end{array}$ & $\begin{array}{l}\overline{\text { L-AH }} \\
\overline{-} \\
\overline{-}\end{array}$ & $\begin{array}{l}\text { (3) } \\
= \\
-\end{array}$ & $\begin{array}{l}E \\
\bar{E}\end{array}$ \\
\hline
\end{tabular}

$\mathbf{R}=$ right $; \mathbf{L}=$ left $; \mathbf{T A}=$ tibialis anterior $\mathbf{M S}=$ soleus (medial part); EDB = extensor digitorum brevis $; \mathbf{A H}=\mathbf{a b d u c t o r}$ hallucis.; $+=$ only TA and MS muscles studied;

$*=\mathrm{H}$ reflexes present MS all patients before and after stimulation;

* = initial F1/Ex ratios greater than 1.5.

(1) persistence L-TA less than $10 \%$; (2) persistence R-EDB less than $10 \%$; (3) only $\mathrm{H}$ reflexes obtained before stimulation.

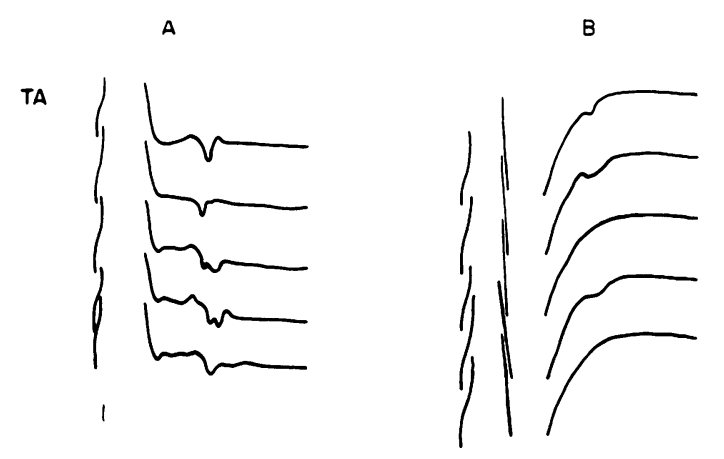

MS

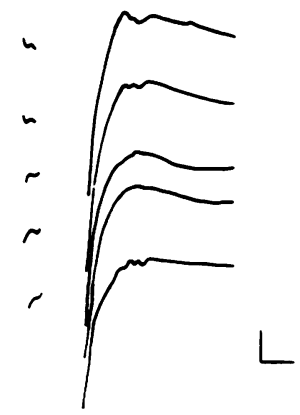

Figure Mean values for $F$ persistence. Studies with an $F$ persistence of zero are not included.

for the right TA/MS (2.05) and EDB/AH (3.0) as well as the left TA/MS (2.24). The ratio for the left EDB/AH was borderline (1.35). With bilateral cerebellar stimulation, ratios within normal limits were found for both sets of muscles on the right; unfortunately, adequate responses using supramaximal stimuli could not be obtained for either the TA or EDB on the left. With and without cerebellar stimulation, $\mathrm{H}$ reflexes were present in the left TA and both AH and MS muscles. By contrast, case 4 had $H$ reflexes in all muscles tested before cerebellar stimulation, that is, the MS, TA, and AH muscles bilaterally (as well as in both abductor pollicis brevis muscles stimulating the median nerves at the wrists). Two other patients (Table 2), case 5 (bilateral stimulation) and case 6 (right stimulation), had $H$ reflexes in fewer muscles after cerebellar stimulation than before.

In case $7, \mathrm{~F}$ amplitude $\mathrm{Fl} / \mathrm{Ex}$ ratios $(\mathrm{TA} / \mathrm{MS}$ and EDB/AH bilaterally) were within normal? limits, and $\mathrm{H}$ reflexes were found only in the MS muscles. There was, however, a pattern of decreased prominence of $F$ responses after cerebellar stimulation (left). $F$ response persistence (10-15 stimuli) in both EDB muscles decreased from about 0.50 to 0.00 , and average $F$ response amplitudes decreased two to three times in all muscles studied except for the right $\mathrm{AH}$, that is, both MS and the left AH (as well as both APB muscles). No $F$ responses were obtained in the TA muscles with or without stimulation.

In the last patient, case 8 , no significant change was found before and after bilateral cerebellar stimulation in $F$ response persistence, amplitude, $F l / E x$ ratios, or average $F /$ maximum $M$ ratios recording from the MS and TA muscles. $H$ reflexes were present only in the MS muscles.

As indicated, four of the patients had bilateral cerebellar stimulation while in four the initial stimulation was unilateral (three right, one left). Given the small number and diversity of the patients in this study, it is not surprising that no conclusions could be reached about differences between these types of stimulation. The data indi- 
cate that unilateral stimulation can have at least contralateral electrophysiological effects. Abnormal $\mathrm{Fl} / \mathrm{Ex}$ ratios in $\mathrm{AB}$ and $\mathrm{MJ}$ were found to be within normal limits after contralateral stimulation. Clinically, this was associated with bilateral decreases in tone.

The predominant clinical finding with cerebellar stimulation was a decrease in tone. At the time of the post-stimulation electrophysiological studies, at least some decrease in tone was noted in seven of the eight patients (all except case 7), although this did not remain a consistent finding on follow-up in case 4 . These changes were most marked in case 1 and least in case 8 . In only one patient (case 5) was there a definite decrease in phasic stretch reflexes, and even here these reflexes were still somewhat hyperactive. The evaluation of myotatic reflexes, however, was obviously made in the context of alterations of tone, and right ankle clonus was found only after stimulation associated with a decrease in tone. As noted in Table 1, only two of the eight patients had clear Babinski responses. Further studies are, therefore, needed to clarify the effect of cerebellar stimulation on this response.

A detailed clinical discussion of the patients studied in this report is planned. Subjectively, all eight patients felt that cerebellar stimulation was beneficial. At least some clinical changes could be defined in all the patients with stimulation. What is most important here is that there was no obvious relation in this series of patients between the electrophysiological changes with cerebellar stimulation and the degree of objective improvement in functional capabilities. The most marked functional improvement in fact has been found in case 8 who was able to walk using crutches only after stimulation. It is this patient in whom no electrophysiological abnormalities were found before stimulation and in whom no changes could be defined after stimulation.

\section{Discussion}

The electrophysiological changes found in these eight patients after cerebellar stimulation can be summarised as follows: reversal of abnormal $\mathrm{F}$ amplitude $\mathrm{Fl} / \mathrm{Ex}$ ratios (cases 1, 2, and 3); decreased presence of $\mathrm{H}$ reflexes in at least one muscle (cases 4,5 , and 6); and decreased prominence of $F$ responses (case 7 ).

$H$ reflexes are normally only obtained in a limited number of muscles, particularly the triceps surae in the lower extremity. Other than in newborns and infants (Thomas and Lambert, 1960), a more widcspread presence of $H$ reflexes occurs in abnormal states (Magladery et al., 1952; French et al., 1961; Thorne, 1965) and has been considered an "indication of chronic upper motoneurone dysfunction" (Garcia-Mullin and Mayer, 1972). On the other hand, responses with the characteristics of $\mathrm{H}$ reflexes may appear in a wider distribution in normal states with muscle contraction (Hagbarth, 1962), and this may also alter the responses obtained with supramaximal stimulation (Upton et al., 1971). Little if any baseline muscle activity was present in the data analysed so that it is unlikely that contraction of the muscle from which the responses were recorded was a major determinant in the results. Nevertheless, we have found in our laboratory (Garcia and Fisher, unpublished observations) that patterns of muscle activity such as contraction in antagonistic muscles can alter both $\mathrm{H}$ reflexes and $F$ responses. Even if this were present during some of the recordings in the patients reported here, the results would still be valid. If one of the effects of cerebellar stimulation were to alter patterns of muscle contraction and this in turn affected $\mathrm{H}$ reflexes and $F$ responses, this is precisely what we wish to measure.

A more serious question is the specificity of the physiological changes noted with cerebellar stimulation. That physiological effects can be demonstrated within this time framework is consistent with the observations of others (Upton and Cooper, 1976; Penn et al., 1978). In a general sense, the inhibitory effect of cerebellar stimulation on $\mathrm{H}$ reflexes and the prominence of the $\mathrm{F}$ response is also consistent with the previous reports (Upton and Cooper, 1976). In the one patient in this series with abnormal $\mathrm{F}$ response $\mathrm{Fl} / \mathrm{Ex}$ ratios studied by other physiological tests, decreased cocontraction was found in the TA and MS muscles at a time when the $F$ amplitude ratios in these muscles were found to be within normal limits. (Penn et al., 1978, Fig. 2). In other words, both types of studies indicated a change in the relative excitability of flexor and extensor motoneurone pools. Finally, the data are all consistent with cerebellar stimulation affecting segmental motoneurone pools. As cerebellar stimulation clearly can produce clinical changes, and indeed such changes have been noted to progress for prolonged periods (Cooper et al., 1976; Penn and Etzel, 1977; Penn et al., 1978), it seems reasonable to believe that cerebellar stimulation does have physiological correlations. It seems equally reasonable that at least some of these correlations would be manifest at the segmental level.

The data suggest that cerebellar stimulation has at least two separate physiological effects. In the 
one patient (case 3 ) with both diffuse $H$ reflexes and abnormal $F$ amplitude $\mathrm{Fl} / \mathrm{Ex}$ ratios, cerebellar stimulation affected only the latter. The changes in the $F$ responses would be most consistent with direct alterations of motoneurone excitability. Although this could also affect $\mathbf{H}$ reflexes, there is evidence that the primary influence on these reflexes relates to presynaptic inhibition. Vibratory inhibition of $\mathbf{H}$ reflexes is probably presynaptic in origin (Gilles et al., 1969; Barnes and Pompeiano, $1970 \mathrm{a}, \mathrm{b})$; the more restricted distribution of $\mathrm{H}$ reflexes with maturation may be due to similar mechanisms (Mayer and Mosser, 1973); and $H$ reflexes are readily elicited at times when $F$ response studies indicate decreased motoneurone pool excitability-that is, early after strokes (Fisher et al., 1975, 1976, 1978). By analogy, the primary effect of cerebellar stimulation on $\mathbf{H}$ reflexes may be presynaptic in origin.

The major clinical effect of cerebellar stimulation was decrease in muscular tone. It is easy to conceive how either a decrease in motoneurone pool excitability or normalisation of the relationship between flexor and extensor motoneurone pools could affect tone. At the same time, the relation between the physiological changes and the much more complicated but clinically more important issue of functional improvement is not obvious. The effects of cerebellar stimulation are complex, involving not only physiological but also chemical (Wood et al., 1977) parameters, and the ultimate question is the summation of these effects on integrated performance in a severely damaged motor system. Nevertheless, it is interesting that in the two patients with the most marked functional improvement with cerebellar stimulation (cases 5 and 8), one had increased tone and myotatic reflexes but little movement disorder while the other had a prominent movement disorder with relatively little abnormality of tone and reflexes. It may be that cerebellar stimulation exerts its most significant therapeutic effect not in "correcting" motor system abnormalities but in producing a better balance between damaged and relatively undamaged motor subsystems.

The technical assistance of Ms Barbara Karakusis is acknowledged gratefully.

\section{References}

Barnes, C. D., and Pompeiano, O. (1970a). Inhibition of monosynaptic extensor reflex attributable to presynaptic depolarization of the group Ia afferent fibres produced by vibration of flexor muscle. Archives of Italian Biology, 108, 233-258.
Barnes, C. D., and Pompeiano, O. (1970b). Presynaptic and postsynaptic effects in the monosynaptic reflex pathway to extensor mononeurons following vibration of synergic muscles. Archives of Italian Biology, 108, 259-294.

Cooper, I. S., Crighel, E., and Amin, I. (1973). Clinical and physiological effect of stimulation of the paleocerebellum in humans. Journal of the American Geriatric Society, 21, 40-43.

Cooper, I. S., Riklan, M., Amin, I., Woltz, J., and Cullinan, T. (1976). Chronic cerebellar stimulation in cerebral palsy. Neurology (Minneapolis), 26, 744753.

Dow, R. S., and Moruzzi, G. (1958). The Physiology and Pathology of the Cerebellum. University of Minnesota Press: Minneapolis, Minnesota.

Fisher, M. A. (1978). Electrophysiological appraisal of relative segmental motoneurone pool excitability in flexor and extensor muscles. Journal of Neurology, Neurosurgery, and Psychiatry, 41, 624 629.

Fisher, M. A., Shahani, B. T., and Young, R. R. (1975). Suppressive effect of vibration: changes early after a stroke. Archives of Physical Medicine and Rehabilitation, 56, 536.

Fisher, M. A., Shahani, B. T., and Young, R. R. (1976). Quantitative assessment of excitability at segmental levels of the central nervous system caudal to acute lesions. Neurology (Minneapolis), 26, 366-367.

Fisher, M. A., Shahani, B. T., and Young, R. R. (1978). Quantitative assessment of excitability at segmental levels of the CNS following acute rostral lesions. I Study of the F response. Neurology (Minneapolis). In press.

French, J. H., Clark, D. B., Butler, H. G., and Teasdall, R. D. (1961). Phenylketonuria: some observations on reflex activity. Journal of Pediatrics, $58,17-22$.

Garcia-Mullin, R., and Mayer, R. F. (1972). H reflexes in acute and chronic hemiplegia. Brain, 95, 559572.

Gilles, J. D., Lance, J. W., Neilson, P. D., and Tassinari, C. A. (1969). Presynaptic inhibition of the monosynaptic reflex by vibration. Journal of Physiology (London), 205, 329-339.

Hagbarth, K.-E. (1962). Post-tetanic potentiation of myotatic reflexes in man. Journal of Neurology, Neurosurgery, and Psychiatry, 25, 1-10.

Hugon, M. (1973). Methodology of the Hoffman reflex in man. In New Developments in Electromyography and Clinical Neurophysiology. Vol. 3, pp. 277-293. Edited by J. E. Desmedt. Karger: Basel.

Magladery, J. W., Porter, W. E., Park, A., and Languth, H. W. (1952). Electrophysiological studies of reflex activity in patients with lesions of the nervous system. I. A comparison of spinal motoneurone excitability following afferent nerve volleys in normal persons and patients with upper motor neurone lesions. Bulletin of the Johns Hopkins Hospital, 91, 219-244. 
Mayer, R. F., and Mosser, R. S. (1973). Maturation of human reflexes. In New Developments in Electromyography and Clinical Neurophysiology. Vol. 3, pp. 294-307. Edited by J. E. Desmedt. Karger: Basel.

Penn, R. D., and Etzel, M. L. (1977). Chronic cerebellar stimulation and developmental reflexes. Journal of Neurosurgery, 46, 506-511.

Penn, R. D., Gottlieb, G. L., and Agarwal, G. C. (1978). Cerebellar stimulation in man, quantitative changes in spasticity. Journal of Neurosurgery, 48, 779-786.

Shahani, B. T., and Young, R. R. (1976). Effect of vibration on the $\mathrm{F}$ response. In The Motor System: Neurophysiology and Muscle Mechanisms, pp. 189. 195. Edited by M. Shahani. Elsevier: Amsterdam.

Sherrington, C. S. (1898). Decerebrate rigidity and reflex coordination of movements. Journal of Physiology, 22, 319-332.

Thomas, J. E., and Lambert, E. H. (1960). Ulnar nerve conduction velocity and $H$-reflex in infants and children. Journal of Applied Physiology, 15, $1-9$.

Thorne, J. (1965). Central responses to electrical activation of the peripheral nerves supplying the intrinsic hand muscles. Journal of Neurology, Neurosurgery, and Psychiatry, 28, 482-495.

Upton, A. R. M., and Cooper, I. S. (1976). Some neurophysiological effects of cerebellar stimulation in man. Canadian Journal of Neurological Sciences, 3, 237-254.

Upton, A. R. M., McComas, A. J., and Sica, R. E. P (1971). Potentiation of "late" responses evoked in muscles during effort. Journal of Neurology, Neurosurgery, and Psychiatry, 34, 699-711.

Wood, J. H., Lake, C. R., Ziegler, M. G., Sade, J., Brooks, B. R., and Buren, J. M. V. (1977). Cerebrospinal fluid norepinephrine alterations during electrical stimulation of cerebellar, cerebral surfaces in epileptic patients. Neurology (Minneapolis), 27, 716-724. 